\title{
Ezra Pound and Du Fu: Gazing at Mt. Tai
}

Kent $\mathrm{Su}^{*}$

University College London, UK

Corresponding Author: Kent Su, E-mail: yi-kuan.su.13@ucl.ac.uk

\section{ARTICLE INFO}

Article history

Received: Spetember 11, 2017

Accepted: October 28, 2017

Published: October 31, 2017

Volume: 5 Issue: 4

Advance access: August 2017

Conflicts of interest: None

Funding: None

\section{Keywords:}

Ezra Pound,

$\mathrm{Du} \mathrm{Fu}$,

Comparative Literature,

Mt. Tai,

Confucius

\begin{abstract}
Confined to a six-by-six-foot outdoor steel cage, Ezra Pound saw a series of mountain hills from a few miles to the east of Pisa. The poet compared one of these small 800-metre hills to the sacred Chinese Mt. Tai, which becomes the most common geographical name in The Pisan Cantos. Pound's poetic summoning of this particular mountain is related to the fact that Mt. Tai is historically and culturally connected to the philosophy of Confucius, who personally ascended the mountain several times. Pound, as a devout Confucian disciple, closely follows the philosophical doctrines and attempts to mentally trace the footsteps of Confucius. This paper will argue how Pound's poetic evocation of the mountain shares a striking similarity to an eighthcentury Chinese poem called "Gazing at Mt. Tai," which was written by the famous literatus - Du $\mathrm{Fu}$ 杜甫 $(712-770)$. In spite of living in two completely different eras and countries, Pound's and Du Fu's reference to Mt. Tai demonstrates the confluence of their poetic spirits. Neither of them ascended mountain personally. They instead made use of their poetic imagination to follow the paths of Confucius and perceived the mountain as an earthly paradise, one which represents tranquillity and serenity away from the moral and physical corruption of the external world.
\end{abstract}

\section{INTRODUCTION}

Ezra Pound (1885-1972), a proponent of modernist internationalism, embraces a vast range of literature and mythical traditions, branching out to incorporate among others, classical Mediterranean culture, the Provençal troubadour tradition, American republicanism and African tribalism. Pound's modernist project thus integrates a broad interdisciplinary range of materials into what he hoped might constitute a "new paideuma," a new vitality of ideas in action (Guide to Kulchur 57-8). "Paideuma" is a term worth juxtaposing alongside his more familiar injunction that is "Make It New." The "It" in "Make It New" refers to the "Old": what is valuable in the culture of the past. Accordingly, Pound only selects the most exemplary art, literature and thought in history. One of the ancient civilisations that Pound deems a significant part of this lifelong poetic project is China, with its distinctive cultures and traditions.

Considering the modest length of this paper, I'd like to focus my attention on Pound's engagement with Tang dynasty poetry, which has been a fascinating topic in modernist studies. Ronald Bush's piece, "Pound and Li Po: What Becomes a Man," in George Bornstein's Ezra Pound Among the Poets focuses on Pound's dramatic monologue in rendering the original verses of Li Po into the emotionally allusive and complex of their English counterparts (40-7). Zhaoming Qian's essay, "Ezra Pound's Encounter with Wang Wei: Toward the 'Ideogrammic Method' of the Cantos," makes use of unpublished archival materials to demonstrate the Buddhist Tang poet's subtle influence on Pound's composition of "Peach Blossom" poetics in Canto IV (267-8). However, there seems to be a lack of scholarly attention paid to the comparative approach between Du Fu and Pound. Pound himself had recognised Du Fu's eminence by reading Herbert Giles's A History of Chinese Literature and Fenollosa's Chinese notes. Pound would later put $\mathrm{Du} F u$ as one of the poets that he had considered of incorporating into Cathay (Qian, Orientalism and Modernism 62). Furthermore, Pound's letter correspondence with a Chinese economist, Zhao Ziqiang, also points out his willingness to publish Zhao's translations of Du Fu's poetry (Qian, Ezra Pound's Chinese Friends 161). Aside from these casual remarks, scholars have not adequately compared or explained the relationship between $\mathrm{Du}$ Fu and Pound.

The present paper thus aims to bring critical attention to the striking similarities of biographical as well as poetic styles between $\mathrm{Du} F u$ and Pound. This article argues that they were both politically active and desired their voices to be heard. They were strong advocates of the philosophy of 
Confucianism and firmly believed that order in the world could be restored through adherence to the teachings of Confucius. In both their cases, their dreams of disseminating their passionate ideas and of achieving political influence failed at the end. I will further my claim to indicate that this sense of defeat and disappointment led them both to evoke the Chinese sacred Mt. Tai.

Although the current paper is by no means comprehensive, it will attempt to fill this critical lacuna of comparison between $\mathrm{Du} \mathrm{Fu}$ and Pound that has generally been neglected by literary scholars. The paper thus begins with a brief biographical comparison of both poets before moving on to address the significance of Mt. Tai in their works. The objective of the paper seeks to argue that in spite of living in two completely different eras and countries, Pound's and $\mathrm{Du}$ Fu's reference to Mt. Tai demonstrate the confluence of their poetic spirits. Unable to ascend Mt. Tai physically, both poets envisage themselves following the trails of Confucius and perceive the mountain as an earthly paradise, one which symbolises purification and the harmonious unification of nature and humanity away from the moral and physical corruption of the external world.

\section{BIOGRAPHICAL SIMILARITIES}

$\mathrm{Du} \mathrm{Fu}$, often considered to be one of the greatest Chinese poets along with Li Bai (701-762), is often associated with the name, “poet historian” 詩史, for his astute observation of actual events. His poems mostly include minute details ranging from the food he has eaten, the medicine he has taken, or names of the servants at his household (Owen liv-lv). The eleventh-century scholar official Su Shi 蘇軾 (1037-1101) praised him in these terms: "not for the space of a meal did he forget his sovereign" (Chou 25). Another prominent scholar, Huang Tingjian 黃庭堅 observed of his poetry that there was "no word without a source" (Luo 498). Indeed, almost every line Du Fu's poetry can be traced back to particular historical moments in which he comments the changes in social policies, shows great sympathies to the suffering of the poor, and records momentous event, such as the An Lushan Rebellion (755-763) (Owen liii). His attention to these facts characterises him as the poet historian of his time.

Like $\mathrm{Du} \mathrm{Fu}$, Pound was also a poet historian of sorts. He defined his Cantos as "a poem containing history" in his 1934 essay entitled "Date Line" (86). Since that time, The Cantos have become a significant expression of the modernist ambition to bring the vast swathes of world history to bear on the understanding of modern life. The Cantos include references to precise places, numbers, years, events and a diverse range of historical figures. Key players in his Cantos include fifteen-century soldier and patron of the arts Sigismundo Malatesta, Grand Duke Pietro Leopoldo, American president John Adams, and most importantly Confucius. Pound sought to present and document these figures using different historical materials and evidence. His obsession with factual information was heavily influenced by the Confucian philosophy of zhengming or rectification of names. The verb, zheng, means "to correct;" the noun, ming, means "name." Zhengming appears in Book 13.3 of The Analects in which Confucius explains that if ming was not corrected, the language would not make sense; as a consequence, laws and rites would not be followed, which would in turn lead to the collapse of society (49). Pound believed that we should control the actuality of things and poets in particular are responsible for maintaining linguistic precision to further intellectual progress, moral perfection and social stability. Poetry, Pound believed, allows for the highest degree of perfection in language, and therefore needs to be as accurate as possible. The idea of precision thus appears in specific figures, concepts or locations through The Cantos.

In addition, $\mathrm{Du} \mathrm{Fu}$ also has a common epithet called the “poet sage" 詩聖, which symbolises his similarity to another great sage of China, Confucius. In The Analects, Confucius repeatedly emphasises the importance of following the ancient emperors as the exemplary models of virtues and values. For instance, in Book 8.19, Confucius outlines that "Great indeed was Yao as a ruler! Sublime indeed was he! It is only Heaven that may be deemed great, but only Yao modelled himself upon it" (30). This statement points out that Confucius harked back to the lost golden age rather than looking forward to a new age in China. He insisted all of his life that his purpose was not to introduce anything new into Chinese society but to restore what was good about antiquity. Many of Du Fu's poems frequently insist on adhering to the forgotten glory and achievements of the past. One of his works, "Respectfully Presented to Vice-Director of the Left, the Senior Wei: Twenty-two Couplets 奉贈韋左丞丈二十二 韻," stands as the primary example:

I thought that I would stand out as quite exceptional, and at once occupy some crucial position.

I would make my lord greater than Yao or Shun,

and cause our customs again to be pure (trans. by Owen, 51)

The tone is lamenting and regret-filled. Du Fu deplores his failure to receive a proper official position in the royal court, one that would enable him to prove his loyalty, competence and moral righteousness to the emperor. He believes that the emperor, lacking the expert and appropriate consultation, cannot gain the legendary status of the ancient sages Yao and Shun.

Like Du Fu, Pound was a devout disciple of Confucius. Through tireless translations of Confucian texts, Pound was convinced that in order for the West to heal itself - to gain order and harmony - it needed to espouse the moral philosophy of Confucius. Pound aimed to disseminate the sage's thinking to a general audience in the West and believed that Chinese civilisations could create another "renaissance" of cultures in a modernist context ("The Renaissance: I-The Palette" 228). Like Du Fu, Pound frequently mentions the ancient Chinese sages, such as Yao and Shun, who were all paragons of virtues and who assisted in the creation of Chinese culture. Pound emphasized their stature in the forms of ideograms, compelling the reader to remember them visually. Their names occupy more than half of a page in Canto 53 (263):

YAO 堯

CHUN 舜

YU 禹 
Both Du Fu and Pound aspired to employ their belief in the Confucian doctrines of duty and responsibility. However, they ultimately failed in their political aspirations. Du Fu's goal was to become a scholar official and civil servant for his country. His dreams of giving advice to the emperor and becoming politically active in the royal court nonetheless were thwarted because he did not pass the imperial examination. This failure to gain prestige compelled him to leave his hometown. Self-exiled, he spent the rest of his life in different parts of the country (Hsieh 3).

Similarly, Pound actively wanted to be involved in the political realm. Writing from his home in Rapallo, he went so far as to send Roosevelt a letter with a copy of the title page of his $A B C$ of Economics in 1933 (Wilhelm 81). Pound became disillusioned with Roosevelt's ability to see the cause of the country's crises. He desired to persuade the president to experiment with Social Credit as a solution to the Great Depression. After receiving no reply from the President, he eventually turned his attention to supporting Mussolini as an exemplar of world order and began to promote pro-fascist sympathies in broadcasts from Rome (Moody 24). These would lead to his eventual incarceration in Pisa.

$\mathrm{Du} \mathrm{Fu}$, a self-exiled poet with no political and scholarly future, led a life of aimless wandering, and Pound, an ostracised poet, was imprisoned on account of his fascist beliefs. It was at these lowest points of their lives that $\mathrm{Du} F u$ and Pound would both evoke Mt. Tai as their symbol of earthly paradise.

\section{THE CULTURE AND HISTORY OF MT. TAI}

Before examining the specific similarities these writers demonstrate in their work, I'd like to offer some exploratory remarks on why they would summon this specific mountain in their poetry. Mt. Tai, rising to an elevation above sea level of approximately 1545 metres, is not a particularly high mountain. Its significant geographical location nonetheless enhances its prominent stature in China. It is located near Qufu city in Shangdong Province. During the Zhou period (ca. 1050-221 BCE), this city was known as the Lu state, and it was the home of the famous philosophical sages, Confucius and Mencius. These two sages ascended the mountain several times during their lives: "[W]hen [Confucius] ascended Mount Tai, he felt that the Empire was small" (Mencius 187). Mencius' statement regarding Confucius underlines how Mt. Tai becomes a symbol of clarity and far-sightedness because it enables the climber to see the world from a different perspective. The mountain's historical association with Confucius appealed to many people from all walks of life and motivated them to trace his footsteps.

For examples, emperors would undertake a "royal regulation," an important concept outlined in one of the Confucian Five Classics, Book of Rites (more specifically in Book 3). It entailed their travelling to the peak of the mountain to pray for the prosperity of the empire and the longevity of their dynasty. Further, illiterate peasants would bury the ashes of their deceased ancestors on the peak to ensure the well-being of their descendants, a practice referred to in Book 3.6 of The Analects. Among important visitors to Mt. Tai were the literati, including poets, writers, and scholar-officials who sought to share Confucius's poignant experience on Mt. Tai. They even erected a temple to honour Confucius at the mountain's summit (Dott 30). The natural setting of Mt. Tai, with the escape it offered from the physical corruption of the world, gave these literati an opportunity for contemplation, spiritual enlightenment and moral self-cultivation-philosophical tenets that Confucius repeatedly emphasised in The Analects $(4.15,6.18,6.21,7.15,7.18)$.

Poets from different dynasties, such as Lu Chi 陸機 (261303), Xie Daoyu 謝道䀍 (340-399), and Hsieh Lingyun 謝 靈運 (385-433), attempted to trace the sage's footsteps, and they all penned their awe-inspired feelings upon encountering the mountain with the unanimous title of "A Chant to Mt. Tai” 泰山吟 (Kroll 225-8). Li Bai (701-762), another important Tang Dynasty poet, wrote a series of six poems on Mt. Tai in 742.His poems are full of mystery, encounters with immortals and failed excursions into the clouds. Li Bai's ascent gives the reader a rare glimpse into the transcendent realm away from the decaying world of humanity. However, he ends the poems with a tone of disappointment, because he has failed to gain immortality despite reaching the peak. Mt Tai thus becomes a sort of an intermediary between the mundane aspects of the earthly realm and the more mysterious powers present in the heavens (Dott 62).

\section{DU FU AND "GAZING AT MT. TAI"}

In 735, in his twenty-fourth year, Du Fu sat for the jinshi imperial examination that was the most prestigious of the entry points to officialdom. As mentioned before, he failed the exam and began his self-imposed exile and travels across the country. He left to go to east to see his father, who was an assistant prefect in the Shandong Province (Hsieh 3). As mentioned earlier, Mt Tai is located in the province, and it has thus been reasonably assumed that Du Fu visited Mt Tai around this time, and there composed one of the most famous poems dedicated to the sacred mountain:

How is Daizong?

Turquoise fields stretch beyond the states of Qi and Lu.

The spirit and beauty of its creation,

its slopes split the yin-yang of dawn and dusk.

Its rising clouds overflow into my chest,

homecoming birds fly through my eyes.

I should climb to the summit

and in one glance see all other mountains dwarfed. (trans. by the author)

In "Gazing at Mt. Tai" Du Fu's emphasis is on the effect of looking at the mountain from afar. This different focus sets him apart from other literati who had personally ascended Mt. Tai. This emphasis persists for some time before he psychologically transports the readers to the summit of the mountain. In other words, he imagines himself on a journey to the top, and his readers are carried with him as he describes his vision.

In the opening line of Du Fu's poem, the speaker attempts to convey his indescribable emotional state upon his first sight of Mt. Tai. He uses the honorific title, "Daizong," to refer to the mountain, thus demonstrating his feelings of awe and 
admiration. The next line shows that the mountain stretches throughout the realms of Qi and $\mathrm{Lu}$, that is, throughout the ancient states of Qi (lying to the north of Mt. Tai) and Lu (lying to the south of it). The Lu state was home to Confucius and Mencius. As aforementioned, these two sages ascended the mountain several times before Du Fu ever set eyes on it. $\mathrm{Du} F u$ is aware of this fact and subtly makes this historical association in the opening lines in his poem.

$\mathrm{Du} \mathrm{Fu}$ then affirms the sacred nature and perfect holiness of the mountain by describing its massive physical structure. The mountain's northern and southern sides divide night from the day: some areas are shaded, while others are sunlit. This contrast can be interpreted as representing the opposing principles of yin and yang. In nature, yin commonly represents the feminine and dark, and yang is frequently associated with the male and light. The universe thus operates by the complementary interaction of the two cosmic forces.

Following this affirmation, the poet offers a close and detailed observation of the mountain's surface. The poet imagines himself flying in the sky. The high clouds seem to originate in his chest, and his eyes appear to burst as he strains to follow the flight of birds returning to their roosts on the mountain. In the concluding couplet, the poet envisions what it would be like to be on the summit, which he promises himself to make someday. This promise is reminiscent of Confucius's experience. However, Du Fu does not physically climb the mountain as Confucius did. He mentally ascends the peak to admire the scenery, thus eliminating the distance between himself and mountain through the use of his imagination.

\section{MT. TAI IN THE PISAN CANTOS}

When Ezra Pound wrote The Pisan Cantos he had not climbed Mt. Tai. In fact, he had not even visited Asia. He was dependent on secondary texts for his depiction of symbolic landscapes. As such he engages in an imaginative journey-one in which his readers are able to vicariously experience what being in Asia is like. Pound used Confucius's Four Books and Five Classics to gain his knowledge of Mt. Tai. These writings are filled with passages regarding the historical and cultural complexity of the mountain. Pound was working on the translations of these Confucian texts, more particularly Mencius, just before being arrested and taken away. Pound quickly pocketed two books: a single-volume edition of the Confucian Four Books, and a small Chinese-English dictionary (Moody 111). Even though Pound only had limited access to these sources while he was imprisoned, his profound engagement with and understanding of Confucian texts enabled him to evoke the sacred Chinese mountain at the lowest point of his life.

In the entire sequence of The Pisan Cantos, Pound evokes the sacred mountain a total of nineteen times. This intensive engagement with Mt. Tai deserves a properly comprehensive research of its own, which is quite beyond the scope and length of this paper. Instead, I want to talk briefly about one aspect of the significance of translating Mt. Tai in Pound's work. Pound's dependency on Confucian texts results in Mt. Tai in The Pisan Cantos being, like Confucius's work before him, at the centre of a literary journey, and it becomes a place that serves as a temporary haven for weary travellers. Pound is able to psychologically escape the hellish environment of the DTC army camp through the evocation of Mt. Tai.

The summoning of Mt. Tai in Canto 77 particularly shares a striking similarity with the tone and theme of Du Fu's poem on the same subject:

Agada, Ganna, Silla,

And Mt Taishan is faint as the wraith of my first friend who comes talking ceramics;

mist glaze over mountain

"How is it far, if you think of it?"

After voyaging through the African history of Wagadu, the poet arrives at the sacred Chinese mountain. Pound compares the mountain to the phantom of his "first friend." Critics present a few possibilities for the identity of this friend. The most likely answer is William Brooke Smith, who was Pound's painter-friend during his first year at university and who died of tuberculosis in 1908. Pound dedicated his first collection of poetry, A Lume Spento, to Smith, calling him "mini caritate primus," which is Latin for "my first friend." The reference may also be to the sculptor Gaudier-Brzeska, Pound's most beloved friend and colleague during his London years (Cheadle 249). Another possibility is Elpenor, whom Odysseus' encounters in Book XI of the Odyssey and who is left behind on Circe's island, dead from a drunken misstep on a ladder. The word "wraith" recalls the previous section's ritual of nekyia in which Elpenor's spirit, distraught that his body has not been given the proper funeral rites, comes from Hades' hell as the first shade and friend to ask the Homeric hero for burial. Pound's connection of Mt. Tai with the apparition of someone he knows dearly seems to imply feelings of nostalgia, remorse and yearning for the return of this earthly paradise.

Two remarkable ideograms appear in this section of The Cantos: “何遠.” They are taken from Book 9.31 in The Analects, which involves a conversation between Confucius and his disciple, $\mathrm{Zi}$ Han. Here $\mathrm{Zi}$ Han asks, "The flowers of the cherry tree/How the petals wave and turn./How could it be I do not long for you?/But your home is so far distant." and Confucius says, "It is the want of thought about it. How is it distant?" The conversation between Confucius and his disciple reflects the classic example of ancient Chinese poetic tradition in which the scenery or jing 景 is symbolically connected to the subtlety of the emotions or qing 情displayed by the speaker. Through the harmonious fusion of the two, the external landscape vividly captures the human sentiment expressed in the lines. In other words, the disciple, $\mathrm{Zi} \mathrm{Han}$, links the flowers on the tree to the person in his mind and begins to ponder how distance is an obstruction between relationships. Confucius responds by saying that distance is not an issue as long as one's mind is clear of all depraved thoughts, which echo the passage in Book 2.2 of The Analects. In other words, the thought itself is what creates the sense of distance

Ron Bush's archival materials demonstrate that Pound originally gives four Chinese characters, “思也何遠, ” in the typescript ("Confucius Erased" 178). Pound's decision of 
choosing the final two words thus implies a greater nuance in the evocation of emotional effect, which is noticeably subdued in the published version. Shortly after printing the two ideograms, Pound offers a brief translation: "How is it far, if you think of it?" By using the second person pronoun, Pound adopts the persona of Confucius and addresses the reader in a didactic tone. The two Confucian ideograms emphasise that as long as one possesses the capability of imagination, one could eliminate the concept of physical distance between each other. As in Du Fu's poem, this elimination of distance enables Pound to mentally reach the mountaintop, where he can temporarily enjoy glimpses of a tranquil landscape of "mist over glaze" as quoted in the section above. The unfrequented and uninhabited Mt. Tai is thus the symbol of serenity and peace beyond time; it represents the psychological fulfilment of the poet who has maintained a vision of an earthly paradise.

By summoning Mt Tai in The Pisan Cantos, Pound, as the first Westerner who makes references to the sacred peak, intuitively inherited a long tradition of literary lineage and recreated classical Chinese poetic vision in the present time. Similar to Li Bai, Du Fu and others for tracing the footsteps of Confucius, Pound stands for an example of a Chinese literatus, who desires to retreat to the mountaintop for separation, purification, and escape from moral and physical corruption. Their eventual goal is to undergo a spiritual quest for harmony and self-cultivation on the mountain. In Pound's case, the peak becomes a mental paradise towering above his Pisan limbo. The evocation is thus necessary for him for temporarily liberating him from the hellish environment.

\section{CONCLUSION}

At first glance, the temporal and cultural differences between Ezra Pound and Du Fu would point to the futility of seeking commonalities in their work. However, after scrutiny, their biographical details and poetic styles are noticeably comparable. Their ill-fated political ambitions compelled them to retreat to Mt. Tai, which symbolises the evocative site of their poetic affinity. Despite the fact that they did not ascend the sacred peak, their imagination enabled them to eliminate the geographical distance. This paper has shown that Pound's engagement with the literary tradition of Tang Dynasty poetry opens up to a rich plethora of new research in this ongoing interest in East/West literary comparativism. The possibility of comparing Pound with different Tang poets has yet to be written. For instance, Wang Changling's 王昌齡 (698-756) poignant verses regarding the hardships of battles in the borders and frontiers can be vividly juxtaposed with Pound's disillusionment in World War I. Another Tang poet of focus could be Han Yu 韓愈 (768-824), whose devotion of Confucianism and antagonism towards other philosophical schools deserve a compelling connection with Pound's personal fervent support for Confucius. Pound's inheritance of Tang dynasty poetic tradition hence echoes the cultural transmission and internationalism of modernist literature.

\section{REFERENCES}

Bush, Ronald. "Confucius Erased: The Missing Ideograms in The Pisan Cantos." Ezra Pound and China, edited by Zhaoming Qian, University of Michigan Press, 2003, pp. 163-192.

---. "Pound and Li Po: What Becomes a Man." Ezra Pound Among the Poets, edited by George Bornstein, University of Chicago, 1985, pp. 35-62.

Cheadle, Mary Paterson. Ezra Pound's Confucian Translations. University of Michigan Press, 1997.

Chou, Eva Shan. Reconsidering Tu Fu: Literary Greatness and Cultural Context. Cambridge UP, 1995.

Dawson, Raymond, translator. The Analects. By Confucius. Oxford, 2008.

Dott, Brian. Identity Reflections: Pilgrimages to Mount Tai in Late Imperial China. Harvard UP, 2004.

Hsieh, Daniel. "Du Fu's 'Gazing at the Mountain"” Chinese Literature: Essays, Articles, Reviews (CLEAR), vol. 16, Dec., 1994, pp. 1-18.

Kroll, Paul W. "Verses from on High: The Ascent of T'ai Shan." T'oung Pao, vol. 69, no. 4-5, 1983, pp. 223-60.

Lau, D.C., translator. Mencius. By Mencius. Penguin, 2004.

Luo, Yuming. A Concise History of Chinese Literature. Brill, 2011.

Moody, A. David. Ezra Pound: Poet: Volume III: The Tragic Years 1939-1972. OUP, 2015.

Owen, Stephen. The Poetry of Du Fu. De Gruyte, 2015.

Pound, Ezra. Guide to Kulchur. London: Faber \& Faber, 1938.

---. The Cantos of Ezra Pound. London: Faber and Faber, 1986.

---. “The Renaissance: I-The Palette," Poetry vol. 5, no. 5, Feb., 1915, pp. 227-234.

Qian, Zhaoming. Ezra Pound's Chinese Friends: Stories in Letters. OUP, 2008.

---. Orientalism and Modernism: The Legacy of China in Pound and Williams. Duke UP, 1995.

---. “Ezra Pound's Encounter with Wang Wei: Toward the 'Ideogrammic Method' of the Cantos." Twentieth century literature, vol. 39, no. 3, 1993, pp. 266-282.

Riegel, Jeffrey, "Confucius," The Stanford Encyclopaedia of Philosophy. 2013, https://plato.stanford.edu/archives/ sum2013/entries/confucius/. Accessed 1 August 2017.

Wilhelm, James. Ezra Pound: The Tragic Years 1925-1972. Pennsylvania State UP, 1994. 